\title{
Economic Feasibility of Residential Behind-the- Meter Battery Energy Storage Under Energy Time- of-Use and Demand Charge Rates
}

\author{
Ahmed Zurfi*\$, Ghaidaa Albayati**, Jing Zhang* \\ *Department of Systems Engineering, University of Arkansas at Little Rock, Little Rock, AR 72204, USA \\ **Department of Information Science, University of Arkansas at Little Rock, Little Rock, AR 72204, USA \\ (ajabbas@ualr.edu; gxalbayati@ualr.edu; jxzhang1@ualr.edu)
}

\begin{abstract}
*Corresponding Author; Ahmed Zurfi, 2801 South University Ave, Little Rock, AR, 72204-1099 United States, Tel: +1 501 258 3062, ajabbas@ualr.edu
\end{abstract}

Received: 14.02.2018 Accepted:10.03.2018

\begin{abstract}
The main purpose of this paper is to compare the economic feasibility of behind-the-meter battery energy storage (BMBES) when used with the strategies of time-of-use (ToU) energy arbitrage and demand charge (DC) reduction. The work targets home BMBES systems that are installed at residential premises to save on monthly electricity bills under residential energy ToU and DC rates. Case studies of two commercial home BMBES systems are used to study the savings that the two systems can achieve for a single-family home in the U.S. under the current kWh prices of both electricity and battery storage. To evaluate the achievable monthly savings and their determining technical and economic factors, the mathematical formulation of a residential electricity bill with and without storage is first presented for each strategy. Then, hourly, monthly, and annual simulations of the different case studies are conducted with the System Advisor Model (SAM) software tool. SAM provides a techno-economic model for battery storage systems and enables the application of practical data of ToU and DC rates, and the home load profiles in the simulations. The economic performance of the studied BMBES systems is compared in terms of the cash flow diagram, net present worth and the payback period. The results of this study can provide customers and practitioners with a set of implications on the effectiveness of residential BMBES in ToU energy arbitrage and DC reduction strategies.
\end{abstract}

Keywords Behind-the-meter energy storage, energy arbitrage, demand charge reduction, demand side management, energy storage economics.

\section{Introduction}

Electricity prices for the residential sector in the U.S. have been continually increasing over the course of the last two decades [1]. This increase is attributable to different factors such as increase in fuel cost, increase in maintenance cost, additional expenses imposed by compulsory regulations that require utilities to invest in clean energy according to the Renewable Portfolio Standard (RPS), as well as weather influences. Energy time-of-use (ToU) and demand charge (DC) rates are the main price structures used by utilities as mechanisms to reflect the actual cost of electricity production over long-range periods during the day [2]. Therefore, customers can achieve savings by managing their energy consumption with the strategies of time-of-use energy arbitrage and demand charge reduction [3]. However, effectiveness and appropriateness of energy ToU and DC rates have always been discussed by utility practitioners, legislatures, and customers [4], [5]. Energy ToU rates have been widely used by most utilities in the U.S. Under energy ToU rates, energy prices depend on the hours of the day during which the energy is consumed. Some utilities have recently resorted to residential demand charge rates as another alternative to meet their economic goals under the challenging conditions of increasing production costs and dwindling market expansion [4], [6], [7]. With demand charge rates, residential customers are charged for the peak demand they withdraw throughout the month in addition to energy consumption. By doing so, a share of the expenses utilities spend to upgrade their generation, transmission, and distribution infrastructures to contain the peak demands will be incurred by residential customers as additional charges reflected on the monthly bill if the customers do not manage their electricity consumption. As a result, the idea of adopting demand charges in the residential sector was completely opposed by the residential customers of these utilities [8]. With such pricing structures, customers are impelled to stir their energy consumption away from highpriced hours and thus alter their load profile peaks [9]. However, monetary savings for customers are not the main purpose behind such pricing structures but rather for purposes of power system stability and economy. Without battery storage, managing the energy consumption of 


\section{A.Zurfi et al. ,Vol. 2, No. 1, March, 2018}

residential customers in accordance with ToU energy arbitrage and DC reduction schemes might not align with the customers' needs. Using battery energy storage systems (BESS) allow customers to charge batteries during low price hours and use that energy thereafter during high price hours. However, despite the drop in the prices of battery technologies, installing a home BTMES system is still considered a large capital outlay project for residential customers. Besides, because of their capacity degradation over time, BTMES systems could lose a portion of their technical-economic potentials [10]. Therefore, the profitability of BESS for energy arbitrage and DC reduction is open to question.

\section{Related Studies}

There have been a plenty of research regarding the feasibility of BESS for peak shaving and energy arbitrage in commercial and industrial sectors. Optimization of the size and peak shaving strategy of two types of BESS is presented in [11] and [12] to minimize the monthly demand charge for an industrial customer. [13] studies the economic feasibility of BESS and optimizes its use for demand charge reduction of different commercial buildings in the U.S. Optimal configuration of BESS technology, size, and dispatch for peak shifting of a commercial load under ToU rates is discussed in [14].

Batteries in the residential sector are usually used for increasing the self-consumption of behind-the-meter photovoltaic systems [15], [16]. However, most of the homes in the U.S. are not equipped with PV systems. According to [17], only 400,000 homes used PV in 2013 while the number is expected to reach $900,000-3.8$ million by 2020 . Therefore, herein we study the use of behind-the-meter battery energy storage (BMBES) systems without rooftop photovoltaic (PV) systems as a household appliance utilized for saving on electricity bills. Furthermore, the plug-and-play feature of most of commercial home BMBES units available on the market permit them to be used for such a functionality.

The profile of a certain load plays a significant role in the effectiveness of the strategies of ToU energy arbitrage and DC reduction [13]. For instance, residential load profiles have different behavior in terms of the load factor (the ratio of average power consumption to maximum power over a specific time period, typically one month) in comparison with commercial and industrial loads. The load factor provides insights on the savings that can be achieved by these strategies. To study the behavior of the load factor of residential loads and commercial and industrial loads, an analysis of practical load profiles of different residential and non-residential loads was conducted based on hourly data from Xcel Energy Inc. The load factor of the average weekday for each month of the year was calculated for each category and listed in Table 1 . It can be seen that the load factor of commercial customers such as education buildings is between 0.75-0.8 while industrial loads, which include high-power equipment operated inconsistently, usually experience low load factors [18]. On the other hand, load factors of residential customers lie in-between with a desirable value of 0.6. Profiles with low load factors allow for better saving possibilities because they incorporate high peak demand. Besides, compared to other load categories, residential profiles are typically linked to weather conditions with daily demand peaks in the vicinity of evening hours.

As it was mentioned earlier, BESS are deemed to be "capital-intensive" for residential customers. Furthermore, partial-utilization of BESS in energy management applications is another challenge affecting their profitability [10]. Therefore, efforts have recently been made by researchers to develop and optimize models for multiple value streams of BESS to increase their value by combining different services with both large-scale systems [19], [20] and customer-sited small-scale systems, i.e., BMBES [21], [22]. Thus, investigation of the economic viability of using residential BMBES under the ToU and DC rate structures has been gaining popularity. Such analysis is necessary to assess the additional values that need to be added by other customer-oriented or grid-oriented services to offset the capital cost of BMBES.

In [23], sizing and economic feasibility of a residential battery storage system under ToU pricing are presented by considering different technical and economic factors. However, the battery voltage and current dynamics, and capacity fade are not considered by using a constant watthour model. In [24], the battery dynamics and state of health are taken into account in evaluating the feasibility of different battery chemistries with ToU arbitrage in a residential application. Still, their analysis has a drawback of overestimating the battery profitability because the power converter cost (the $\$ / \mathrm{kW}$ cost) is neglected in calculating the system capital cost. The power converter cost constitutes more than $25 \%$ of the total cost of the battery system [25], and it affects the analysis significantly. Furthermore, the round-trip efficiency of the power converter is not considered in calculating the overall BESS efficiency, i.e., the DC/DC efficiency is used instead of the AC/AC efficiency.

[26] discusses the economic feasibility of using retired electric vehicles' (EVs) batteries in second life for ToU energy arbitrage in residential applications in Ontario, Canada. The shortcoming of this study is that the capacity fade due to the degradation over the second life of the battery is neglected which is an unrealistic assumption. Furthermore, to evaluate the viability of repurposing retired EVs' batteries for residential energy management services, a set of hurdles need to be overcome including the uncertainties in the initial capacity and cost-effectiveness analysis of second-life batteries, and challenging regulations that impede the adoption, and reduce the profitability opportunities of these batteries [27], [28]. In fact, EVs have widely been discussed as a BMBES means for end-user energy management applications [29]. However, the energy storage from EVs is itinerant and available for the grid/ load services only during charging times. Furthermore, charging and discharging of plugged-in EVs must be controlled to give priority to the drivers' requirements of mileage ranges. In other words, the battery state of charge needs to be balanced and maintained within levels sufficient for next driving trips. Another challenge is that using the EV battery for other energy management functions can cause extra deterioration to the battery because such functions impose cycling conditions different than what driving cycles impose for which the battery and its warranty are originally designed [26]. Herein, we study the economic feasibility of new home BMBES 


\section{A.Zurfi et al. ,Vol. 2, No. 1, March, 2018}

units, and second-life batteries are out of the scope of our work.

[30] presents optimal sizing of a battery storage system for peak demand reduction for the residential sector in different regions in Canada. The authors propose a peak shaving dispatch method by setting a grid power target for each residential customer; however, the detailed cost analysis of this method to evaluate the achievable demand charge reduction is not discussed. A lack of research about the feasibility of using batteries for demand charge reduction in the residential sector has been noticed since this rate structure is newly readopted for residential customers. The sparse research in this regard was also reported in [31], which is the only related work that was found in our thorough review of the relevant literature. [31] presents the economic feasibility analysis of using home batteries for demand charge reduction for a typical U.S. house. The profitability of a range of energy storage technologies was evaluated and compared under demand charge rates from Consolidated Edison Company of New York, Inc. For battery storage, the authors adopted the total energy throughput model to determine the battery lifetime. The energy throughput model defines the end-of-life of the battery when a certain amount of watt-hours is cycled through the battery. Although this amount of energy is determined by obeying the standard operational conditions (especially the depth of discharge) in the battery datasheet, the energy throughput model does not reflect the effect of the depth of discharge used in each single charge-discharge cycles. Furthermore, the energy throughput model does not consider the effect of the discharge current rate on the battery energy capacity. Such a factor has a significant impact on the battery degradation.

Furthermore, in the research works reviewed above, the effects of the inflation and escalation of electricity prices are not considered which are important factors in evaluating the profitability of any energy project. [32] and [33] shows that the inflation of electricity prices have a significant impact on the savings that a battery storage system can provide for residential customers under ToU prices. However, the escalation of electricity prices due to factors other than inflation is not considered. Other factors that cause retail electricity prices to rise include supply/demand inequities, increase in fuel costs and retirement of a number of coalfired power plants around the nation due to environmental regulations. This increase can also include the demand charges in addition to the $\mathrm{kWh}$ prices. Therefore, it is necessary to take into account the prices escalation caused by these factors along with the inflation in assessing the feasibility of peak shaving and energy arbitrage strategies.

In this work, we study and compare the economic feasibility of using home batteries with demand charge and ToU rates. By considering the power converter cost as well as different economic and technical factors, we evaluate the saving opportunities that can be achieved by dispatching the batteries accordingly. The System Advisor Model (SAM) software developed by the National Renewable Energy Lab (NREL) with support from the U.S. DoE [34] is used in the analysis. SAM provides a techno-economic battery storage model that is able to portray the battery voltage dynamics, cycling capacity degradation, and thermal behavior. With SAM model, factors such as the discount rate, inflation rate, electricity price escalation rate, battery round-trip efficiency, and depth of discharge can be considered in the battery's feasibility analysis. Two lithium ion BMBES units assumed to be similar to two models of Tesla home batteries that are Powerwall 1-DC, $7 \mathrm{kWh}$ and Powerwall 2-AC, $13.5 \mathrm{kWh}$ are used in the analysis with practical load profiles of a twostory American family house.

\section{Mathematical Formulation}

\subsection{ToU Energy Arbitrage}

Different utilities use different pattern and prices levels of ToU plans. Thus, the general requirements and objectives of ToU energy arbitrage need to be identified before evaluating the feasibility of using BESS under any ToU plan. The main objective of ToU energy arbitrage is to minimize the monthly electricity bill of the residential user. Without demand charges, the residential customer is charged monthly three different costs: the energy cost represents the cost of purchasing $\mathrm{kWh}$ from the utility, the adjustments are additional fees that the utility charges per $\mathrm{kWh}$ for expenses such as renewable energy infrastructure surcharges, fuel clause rider, infrastructure rider, etc., the third part of the bill comes from the fixed charge that is added whether or not the customer uses energy.

electricity bill $=$ energy cost + adjustments + fixed charge

Eq. (1) can mathematically be written as follows

$E B=30 \times \sum_{h=1}^{24}\left[(W(h) \times r(h))+\left(W(h) \times r_{a}(h)\right)\right]+$ $C_{\text {fixed }}$

where

$W(h)$ is the energy consumption during the hour $h$ of the day, (kWh).

$r(h)$ is the energy price in hour $h,(\$ / \mathrm{kWh})$.

$r_{a}$ is the constant rate of adjustment, $(\$ / \mathrm{kWh})$.

$C_{\text {fixed }}$ is the fixed charge, (\$).

Under a ToU plan, the energy price can be defined as follows $r(h)=\left\{\begin{array}{cl}r_{\text {off }} ; & h \in H_{\text {off }} \\ r_{\text {semi }} ; & h \in H_{\text {semi }} \\ r_{\text {on }} ; & h \in H_{\text {on }}\end{array}\right.$

where $r_{o f f}, r_{\text {semi }}$, and $r_{o n}$ are the prices of the off-, semi-, and on-peak hours, respectively. $H_{o f f}, H_{s e m i}$, and $H_{o n}$ are the off-, semi- , and on-peak hours, respectively with

$H_{\text {off }}+H_{\text {semi }}+H_{\text {on }}=24$

Each of the periods $H_{o f f}, H_{s e m i}$, and $H_{o n}$ can contain two or three subintervals over the day. This can be represented as $H_{o f f}=H_{o f f 1}+H_{o f f 2}+\cdots$, and so on for other periods.

When the BMBES system is introduced to the ToU strategy, the electricity bill will be defined as follows

electricity bill with storage

$$
\text { = electricity bill } w / \text { o storage }
$$$$
+ \text { cost of energy for charging }
$$

battery during offpeak -

cost of energy supplied by battery during onpeak

The mathematical representation of Eq. 5, the electricity bill with storage $\left(E B^{\prime}\right)$, is written as follows

$E B^{\prime}=\left[30 \times \sum_{h=1}^{24}\left[(W(h) \times r(h))+\left(W(h) \times r_{a}(h)\right)\right]+\right.$ $\left.C_{\text {fixed }}\right]+D \times\left[\sum_{h \in H_{\text {off }}}\left[\left(\frac{W_{b}(h)}{\eta} \times r_{\text {off }}\right)+\left(\frac{W_{b}(h)}{\eta} \times r_{a}\right)\right]\right]-$ 
A.Zurfi et al. ,Vol. 2, No. 1, March, 2018

$D \times\left[\sum_{h \in H_{\text {on }}}\left[\left(W_{b}(h) \times r_{o n}\right)+\left(W_{b}(h) \times r_{a}\right)\right]\right]$

where $W_{b}(h)$ is the energy supplied by the battery during hour $h,(\mathrm{kWh})$ calculated by integrating the battery power, $P_{b}(t)$, over time as $W_{b}(t)=\int P_{b}(t) \cdot d t$.

Using constant power rate $P_{B}$, the battery energy supplied to the load during one hour will be equal to $P_{B} \times 1(\mathrm{kWh})$.

$\eta$ is the round-trip efficiency of the BMBES.

$D$ is the number of days per month the BMBES is used with ToU.

The monthly saving, $S_{m}$, achieved by using the BMBES with ToU is calculated as the difference between the electricity bill without storage, $E B$, and the bill with the storage, $E B^{\prime}$ as follows

$S_{m}=D \times\left[\left[\sum_{h \in H_{o n}}\left[\left(W_{b}(h) \times r_{o n}\right)+\left(W_{b}(h) \times r_{a}\right)\right]\right]-\right.$

$\left.\left[\sum_{h \in H_{o f f}}\left[\left(\frac{W_{b}(h)}{\eta} \times r_{o f f}\right)+\left(\frac{W_{b}(h)}{\eta} \times r_{a}\right)\right]\right]\right]$

(7)

Introducing the depth of discharge (DOD) of the battery as $q$, the monthly saving can be written as

$$
\begin{aligned}
& S_{m}=D \times q \times\left[\left[\sum_{h \in H_{o n}}\left[\left(W_{b}(h) \times r_{o n}\right)+\left(W_{b}(h) \times r_{a}\right)\right]\right]-\right. \\
& \left.\left[\sum_{h \in H_{\text {off }}}\left[\left(\frac{W_{b}(h)}{\eta} \times r_{o f f}\right)+\left(\frac{W_{b}(h)}{\eta} \times r_{a}\right)\right]\right]\right]
\end{aligned}
$$

(8)

With DOD in mind, the battery is required to be charged to its full capacity during the off-peak hours and fully discharged during the on-peak hours. Therefore, the battery will undergo only one cycle per day at the selected DOD. In other word, the battery size and charge and discharge rates should be selected to achieve the following conditions: $H_{\text {off }} \geq$ the battery charge time; $\quad$ and $\quad H_{\text {on }} \geq$ the battery discharge time. Thus, the monthly saving can be expressed as follows

$$
\begin{aligned}
& S_{m}=D \times q \times W_{B} \times\left[\left(r_{o n}-\left(\frac{1}{\eta} \times r_{o f f}\right)\right)+\right. \\
& \left.\left(r_{a}-\left(\frac{1}{\eta} \times r_{a}\right)\right)\right]
\end{aligned}
$$

where $W_{B}$ is the battery rated energy capacity in kWh. Taking into account the capacity relation (degradation) with the number of cycles, the battery capacity $W_{B}$ is expressed as a function of the number of cycles (days). Therefore, the annual $S_{a}$ from the BMBES system can be written as

$S_{a}=\sum_{m=1}^{M}\left[\sum_{d=1}^{D_{m}}\left[q \times W_{B}(d) \times\left[\left(r_{o n}-\left(\frac{1}{\eta} \times r_{o f f}\right)\right)+\right.\right.\right.$

$\left.\left.\left.\left(r_{a}-\left(\frac{1}{\eta} \times r_{a}\right)\right)\right]\right]\right]$

where $M$ and $D_{m}$ is the number of months per year and days per month the ToU plan provides savings.

To ensure that the battery serviceable capacity will be completely discharged during the on-peak hours of the load, Eq. (6)-(10) show that the battery size and DOD should be selected so that the serviceable capacity is less than or equal to the minimum peak load of monthly load profiles.

\subsection{Demand Charge Reduction}

The savings that can be achieved in month $m$ by using the BMBES under a flat demand charge rate is represented as the difference between the demand charge without storage and the demand charge with storage as follows

$$
S_{m, D C}=\left(P_{\text {peak } 1}-P_{\text {peak } 2}\right) \times r_{D}=\Delta P_{\text {shaved }} \times r_{D}
$$

where $P_{\text {peak } 1}$ and $P_{\text {peak } 2}$ are the peak demand in $\mathrm{kW}$ for the month $\mathrm{m}$ without and with the storage, respectively. $\Delta P_{\text {shaved }}=\left(P_{\text {peak } 1}-P_{\text {peak } 2}\right)$ is the shaved peak power by the peak shaving strategy and it should be supplied by the battery. $r_{D}$ is the monthly flat demand charge rate.

Some utilities use time-of-use demand charge plans in which the demand charge also change with the time of the day/ use. In this case, the savings from demand charge reduction can be expressed as follows

$S_{m, D C}=\left(\Delta P_{\text {shaved,on }} \times r_{D, \text { on }}\right)+\left(\Delta P_{\text {shaved }, \text { semi }} \times r_{D, \text { semi }}\right)+$ $\left(\Delta P_{\text {shaved,off }} \times r_{D, o f f}\right)$

where $\Delta P_{\text {shaved,on }}, \Delta P_{\text {shaved,semi }}$ and $\Delta P_{\text {shaved,off }}$ are the shaved peak power during the on-, semi- and off-peak periods, respectively. $r_{D, o n}, r_{D, \text { semi }}$ and $r_{D, \text { off }}$ are the demand charge during the on-, semi- and off-peak periods, respectively.

\section{Description of the Studied BMBES Systems}

The two studied BMBES units are assumed to be akin to one of the cutting-edge commercial home batteries that are the Tesla Powerwall models. The first system is assumed to be similar to a Powerwall 1 with $7 \mathrm{kWh}$ DC-interfaced. This model does not include the inverter. The second system is assumed to be similar to a Powerwall 2-AC with $13.5 \mathrm{kWh}$. This second generation of Tesla Powerwall comes with an embedded inverter for AC interface. The datasheets of the two generations of the Powerwall are shown in Table 1 [35], [36]. The two units will be referred to as PW1 and PW2, respectively. The efficiency of PW1 at charge/ discharge power rating of $2 \mathrm{~kW}$ is $92.5 \%$ excluding the inverter. The maximum efficiency of batteries inverters available in the market can reach $97 \%$. The round-trip efficiency of the inverter (two-way) is $(97 \% \times 97 \%=94.05 \%)$. Therefore, the overall round-trip efficiency of the PW1 system is $87 \%$. The feasibility of the BMBES units is studied with a load profile of an Arkansan family house. The monthly load profiles of the house were calculated using SAM tool based on the average monthly energy consumption of the house. The load profiles are shown in Fig. 1. It is obvious that such a house requires more than one of each of the studied battery banks to cover its load. However, in our analysis, we focus on the feasibility of a single system used to supply the base load of the house during on-peak hours or to shave the peak demand. The capital cost of the BMBES system includes the costs of the battery pack, inverter, and installation. The price of PW1 is $\$ 3000$ excluding the inverter. Adding $\$ 1500$ for the battery inverter and $\$ 800$ estimated installation cost, the total capital cost of PW1 is $\$ 5300$. These systems need to be installed by a competent technician, and here the installation cost is obtained as estimated by the manufacturer. The price of PW2 is $\$ 5500$ including the inverter. The installation cost is $\$ 1500$ leaving the system with a total cost of $\$ 7000$. It can be noticed that the kWh price of PW2 is lower than PW1.

The datasheets of the batteries under consideration do not provide any information about the capacity-cycles relation. The Lithium-ion chemistry that Tesla uses in home 


\section{A.Zurfi et al. ,Vol. 2, No. 1, March, 2018}

Powerwalls is Nickel Manganese Cobalt Oxide (NMC) [37]. Therefore, a typical lifecycle curve of NMC batteries under different DODs is used. Finally, the end-of-life of the battery is decided when its capacity degrades to $60 \%$ of the original capacity.

Table 1. Datasheets of the assumed BMBES systems.

\begin{tabular}{|c|c|c|}
\hline Specification & PW1 & PW2 \\
\hline $\begin{array}{c}\text { Battery chemistry } \\
\text { Lithium-based }\end{array}$ & 3.3 & 5 \\
\hline $\begin{array}{c}\text { Maximum Continuous Power } \\
(\mathrm{kW})\end{array}$ & 3.3 & 7 \\
\hline Peak Power (kW) & 6.4 & 13.2 \\
\hline $\begin{array}{c}\text { Energy capacity (kWh) } \\
\text { Internal Battery DC Voltage (V) }\end{array}$ & $\begin{array}{c}92.5 \\
\text { w/o } \\
\text { inverter }\end{array}$ & 89 \\
\hline Round-trip efficiency (\%) & \multicolumn{2}{|c|}{100} \\
\hline Depth of discharge (\%) & None & Include \\
\hline Inverter & \multicolumn{2}{|c|}{} \\
\hline Lifetime (year) & \multicolumn{2}{|c|}{} \\
\hline
\end{tabular}
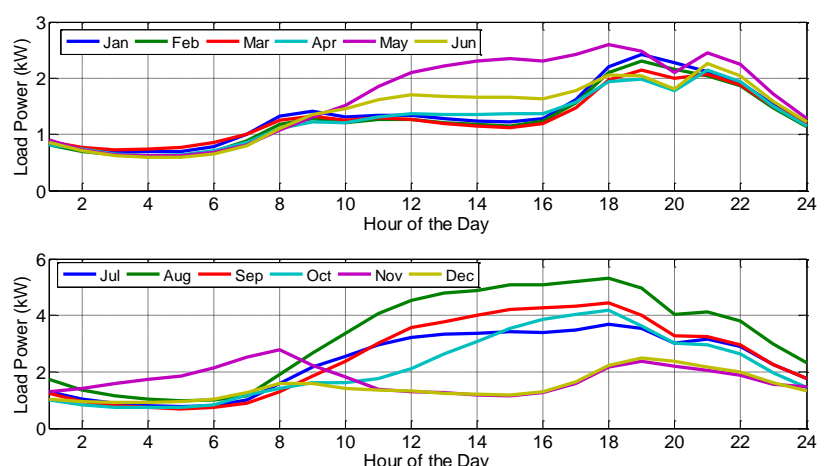

Fig. 1. Monthly load profiles of the studied single-family house.

\section{SAM Simulation Results and Discussions}

SAM simulation of the two BMBES systems, load profiles, batteries dispatch, ToU schedules and financial parameters was used to evaluate the annual savings achieved by the systems. Then, the payback period (PBP) and net present worth (NPW) were calculated from the annual savings. The PBP and NPW are used as two economic metrics to evaluate and compare the systems. The PBP was calculated by the accumulative annual savings (undiscounted) method, i.e., it is the simple payback period. The NPW is calculated as

$$
N P W=\left(\sum_{y=1}^{15} \frac{s_{a}}{(1+r)^{y}}\right)-\text { capital cost }
$$

(11) where $y$ is the year of the cash flow saving. $r$ is the real discount rate calculated from the nominal rate considering the inflation.

The inflation rate for the U.S. is $1.7 \%$ in July according to the 2017 consumer price index report by the Bureau of Labor Statistics of the U.S. Department of Labor [38]. The nominal discount rate is selected to be $6 \%$, and this gives a real discount rate of $4.23 \%$ for our analysis. Both BMBES systems come with a 10 -year warranty. However, it is not mentioned how much energy will exactly be available in the battery at the end of the 10-year period. Moreover, although this can be more reasonable in the application of renewables self-consumption not in daily cycling with ToU, the warranty of the assumed BMBES systems can be optionally extendable to 10 more years. Therefore, the analysis is conducted over a period of 15 years to evaluate the annual savings.

\subsection{ToU Energy Arbitrage}

The two ToU plans used in the SAM simulation and analysis are from Entergy Arkansas Inc. and Nevada Power Co. and their weekday schedules are shown in Fig. 2. They will be referred to as AR and NV, respectively.

A) PW1 with AR plan: Under this plan and without an escalation in electricity prices, the NPW of the PW1 is \$3431. The system will not pay back at the end of the analysis period. The nominal cash flow diagram of the system showing the cash-in is shown in Fig. 3. The effective capacity of the battery at the end of the analysis period is $61 \%$. This means that the battery reached the end of its assumed life. Then, escalation of $1 \%, 2 \%, 3 \%, 4 \%$ and $5 \%$ in the electricity price was applied. The annual savings and NPWs with the escalation effect are shown in Fig. 4. It can be noticed that the annual cash-in increases with the escalation rate because the difference between the ToU onpeak and off-peak prices $\left(\Delta r=r_{o n}-r_{o f f}\right)$ increases (see 10). However, the escalation slightly improved the system's NPW. It can also be noticed that with escalation of $4 \%$ and $5 \%$, the annual saving increases despite the capacity degradation.

B) PW1 with NV plan: In this scenario, the battery dispatch was first programmed to work on weekdays only and kept idle on weekends albeit the NV rate plan provides a saving opportunity on weekends. This is to preserve the battery life. The NPW of the PW1 under this plan is increased to $-\$ 2527$. However, it is still negative, and the system will not be paid back at the end of the analysis period. The cash-in part of the system's cash flow diagram is shown in Fig. 5. With weekdays- only scenario, the battery undergoes only 1290 cycles over the analysis period. As a result, the effective capacity of the battery at the end of the analysis period is $84 \%$.

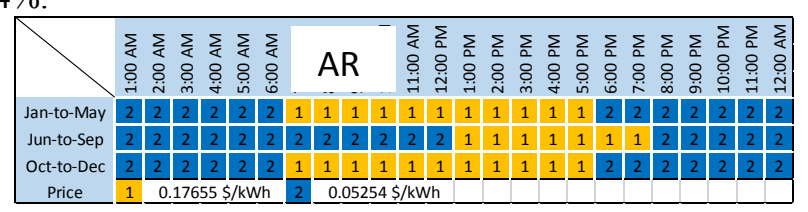




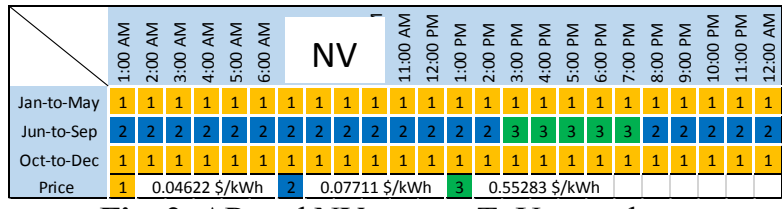

Fig. 2. AR and NV energy ToU rate plans.

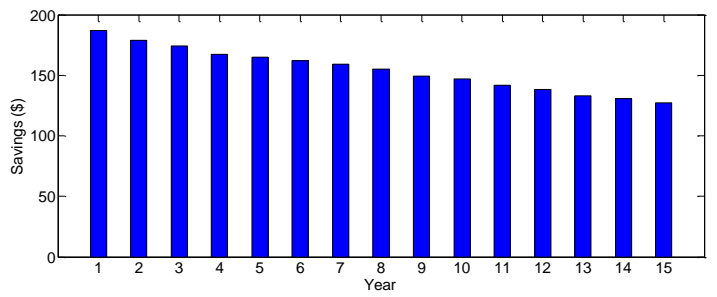

Fig. 3. Cash-in flow diagram of PW1 with AR plan.

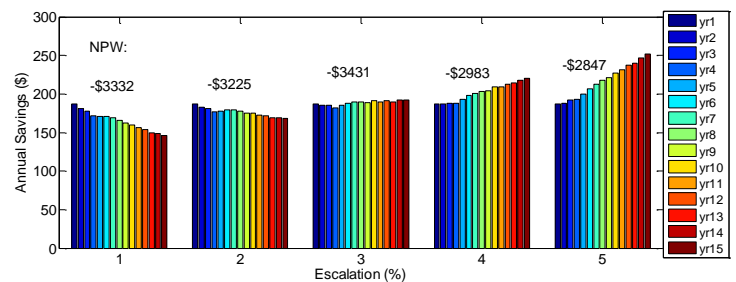

Fig. 4. Annual savings and NPWs of PW1 with AR plan and escalation.

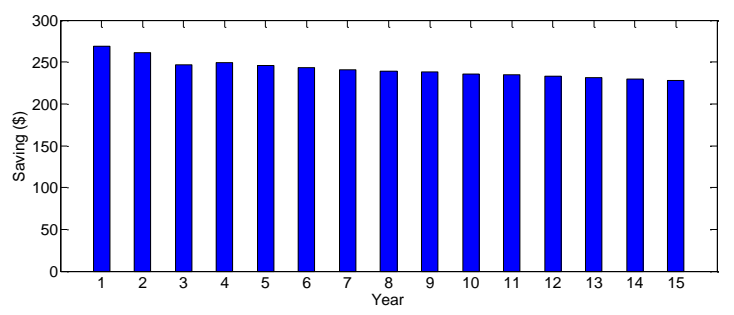

Fig. 5. Cash-in flow diagram of PW1 with NV plan, weekdays-only.

Compared to the case of AR plan, the battery number of cycles is much less, and the battery is left with ample capacity. This is because the battery functions for only four months a year. With the escalation of $5 \%$, the NPW was increased to $-\$ 1573$. Based on the simple PBP, the system paid $97.5 \%$ of its capital investment. With $84 \%$ remaining capacity, the analysis period can be extended one year to achieve $100 \%$ payback. Then, the battery dispatch was programmed to provide ToU savings on weekends too, i.e., seven days a week. This scenario adds 540 more cycles resulting in more savings. The additional annual savings from weekends operation are shown in Fig. 6. Therefore, the system can achieve payback of $94 \%$. However, the NPW of the system is still negative and equals to $-\$ 1536$. With $5 \%$ escalation, the system can pay back in 13 years with a NPW of \$-221.

C) PW2 with AR plan: PW2 has double the capacity of PW1 and this technically implies that, under the same conditions of load, ToU plan, and DOD, the annual savings from PW2 is approximately doubled. To present the savings from this scenario, the average monthly bill without and with the system are shown in Fig. 7. However, the system is still economically infeasible according to its NPW and PBP.

D) PW2 with NV plan: Finally, and similar to the case of PW1, two scenarios of the NV plan were considered: weekdays only scenario and weekdays and weekends scenario. In the first case, the NPW is $-\$ 2055$ and PBP is 16 years. By, scrutinizing the load profile, it can be found that the load consumption during the on-peak hours in the month of June is $9.16 \mathrm{kWh}$ which is less than the PW2 full energy. As a result, the condition of fully discharging the battery during on-peak hours is not satisfied reducing the annual savings. The cash-in flow diagram is shown in Fig. 8. In the weekdays and weekends case, the NPW of the system was increased to $-\$ 214$ and PBP was reduced to 12 years.

A summary of the of the economic performance of the two systems in terms of the NPW and PBP in each scenario is presented in Table 2. It can be noticed that the most profitable scenario is PW2 under Nevada plan when the system is operated the entire week.

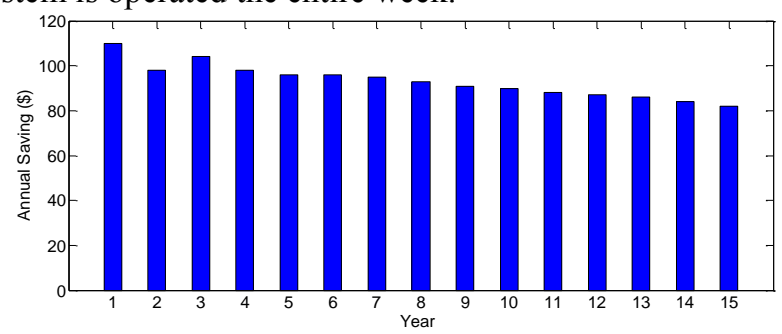

Fig. 6. Added savings from weekends operation of PW1- NV plan.

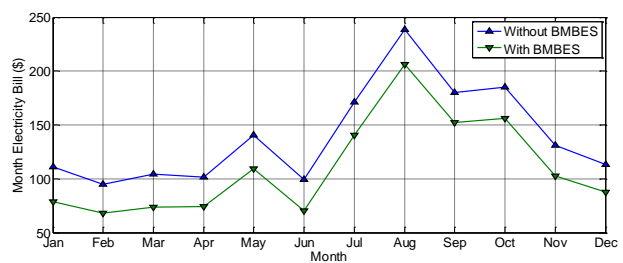

Fig. 7. Average monthly bill with and w/o PW2-NV planweekdays only.

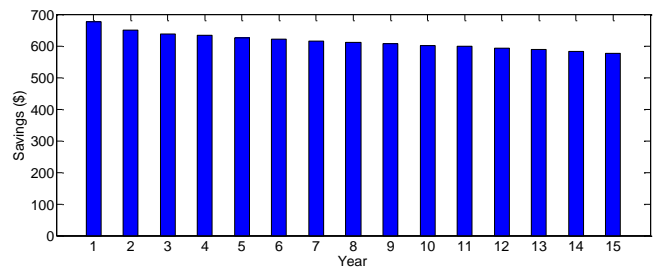

Fig. 8. Cash-in flow diagram of PW2 with NV plan weekdays only.

Table 2. Summary of the economic performance of the two systems.

\begin{tabular}{|c|c|c|c|}
\hline \multirow{4}{*}{} & Scenario & NPW (\$) & PBP (yr) \\
\hline \multirow{2}{*}{ PW1 } & AR-Wdays & -3431 & $>15$ \\
\cline { 2 - 4 } & NV-Wdays & -2527 & $>15$ \\
\cline { 2 - 4 } & NV-Wdays +Wends & -1536 & $\cong 15$ \\
\hline \multirow{2}{*}{ PW2 } & AR-Wdays & -3612 & $>15$ \\
\cline { 2 - 4 } & NV-Wdays & -2055 & $\cong 15$ \\
\hline
\end{tabular}




\begin{tabular}{|l|l|l|l|}
\hline & NV-Wdays + Wends & -214 & 12 \\
\hline
\end{tabular}

E) Break-even Analysis: The break-even (BE) analysis can be represented by substituting (10) in (11) and equating the NPW to zero to evaluate the ToU rate at which the system can achieve break-even. In SAM, the BE analysis was made by changing the escalation rate (technically increasing $\Delta r$ ) to achieve a zero NPW. The BE for PW1 and PW2 under AR plan was achieved at escalation of $17 \%$ and $12.5 \%$, respectively. This is corresponding to a PBP of 12 years and 11 years, respectively. Under NV rate, the BE escalation is $6 \%$ and $0.53 \%$ for PW 1 and PW2, respectively. Fig. 9 and Fig. 10 show the NPW and PBP of PW1 versus $\Delta r$ of AR and NV plans.

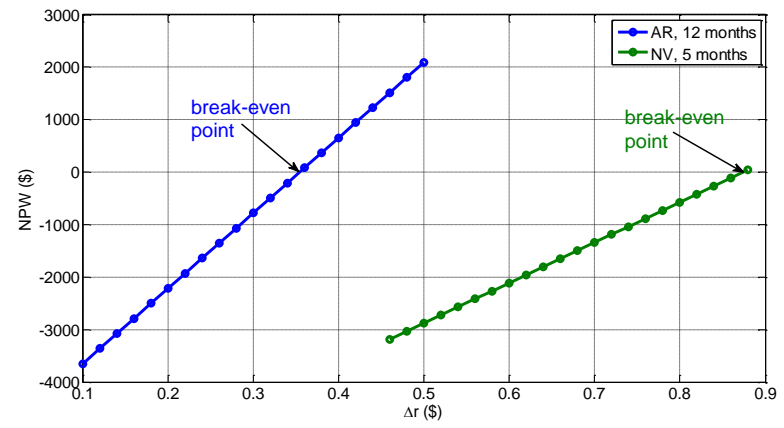

Fig. 9. Break-even analysis of PW1 and PW2, NPW.

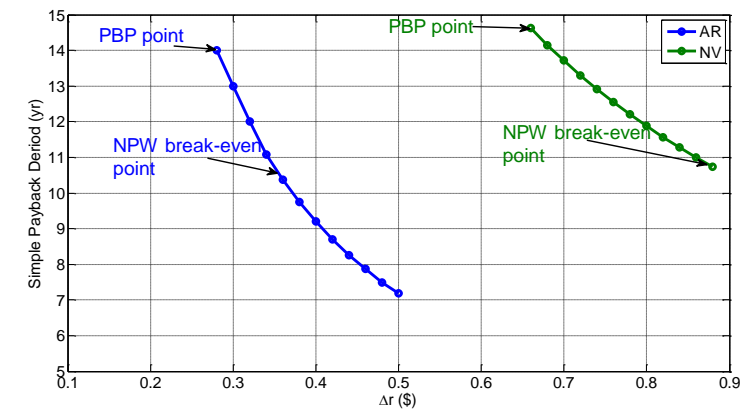

Fig. 10. Break-even analysis of PW1 and PW2, PBP.

\subsection{Demand Charge Reduction}

Different residential plans with flat and ToU demand charge rates were used to evaluate the savings from the peak shaving using the BMBES. SAM provides a peak shaving algorithm by which the battery is dispatched to minimize the load power consumption from the grid. However, the battery was also manually dispatched according to the energy ToU rates to investigate how such a dispatch will save on demand charges in addition to the $\$ / \mathrm{kWh}$ savings. This case was considered by a simulation of PW1 implemented under a residential plan from South Carolina Electric \& Gas Co. This plan contains both energy ToU and flat DC rates. The energy ToU price change is offered for 5 hours a day with a price difference, $\Delta r$, of only $0.013 \$ / \mathrm{kWh}$ for the entire year. The flat DC rate is $\$ 11.94$ from June to Sep and $\$ 8.53$ in the rest of the year. The cash-in flow diagram of the savings from energy ToU and the associated savings from the flat DC is shown in Fig. 11.

It is obvious that both savings are trivial and the BMBES is completely infeasible in this scenario. This is attributed to small price difference in the energy ToU rate. On the other hand, the load peaks do not coincide with the ToU discharge in most of the months. Fig. 12 shows the profiles of the load, battery and grid power for the month of January depicting how the ToU discharge is away from the month peak. Therefore, dispatching the battery according to the energy ToU schedule does not necessarily achieve peak shaving. Thus, a peak shaving algorithm should be used to achieve savings. In fact, demand charge plans do not usually offer lucrative opportunities for energy ToU savings.

Then, a peak shaving algorithm provided by SAM was used under the same plan. Although the algorithm is mainly provided for peak shaving with PV systems, it was used here to evaluate how much a BMBES system can reduce the monthly DC and it is not necessarily the optimal for highest savings. The peak shaving of the month of January is shown in Fig. 13. The cash-in flow diagram of the savings without and with $5 \%$ escalation is shown in Fig. 14. It can be noticed that the system cannot be feasible in both scenarios. After that, different flat DC rates up to $20 \$ / \mathrm{kW}$ were applied with the same peak shaving algorithm. The system deemed to be infeasible for DC reduction under the current prices of battery storage and DC rates.

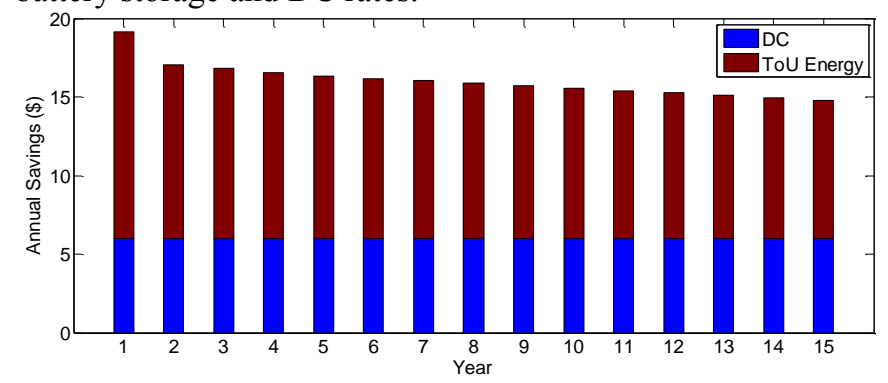

Fig. 11. Energy ToU and DC savings of PW1 with flat DC plan.

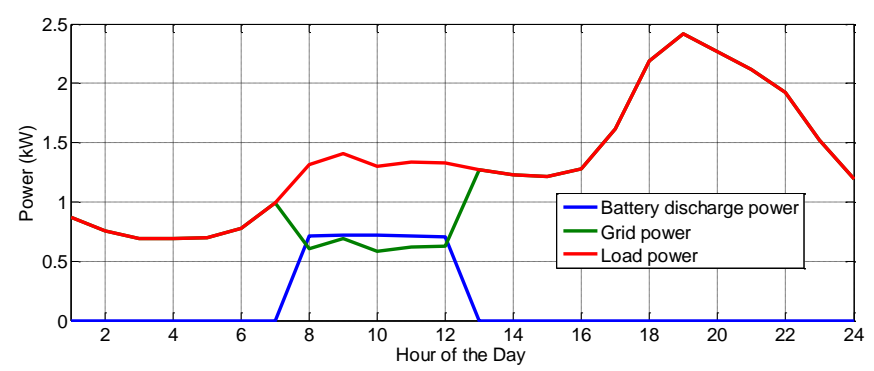

Fig. 12. Load, grid, and battery power under ToU dispatch.

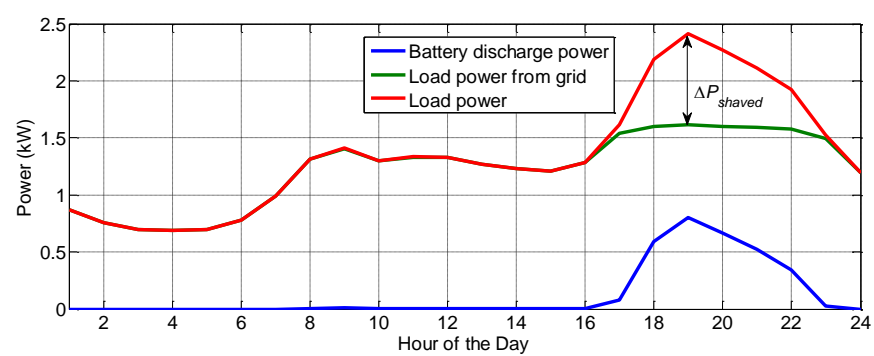

Fig. 13. Load, grid, and battery power under the peak shaving strategy. 
A.Zurfi et al. ,Vol. 2, No. 1, March, 2018

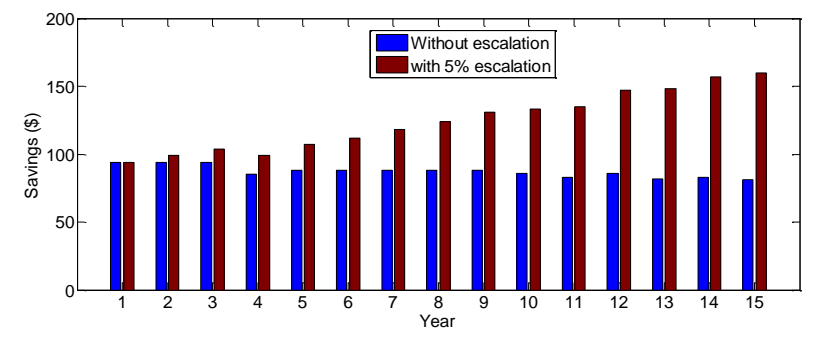

Fig. 14. Cash-in flow diagram of PW1 DC savings with and without escalation.

The studied load profile has an average load factor of 0.592 with average peak power of $3 \mathrm{~kW}$. Therefore, the average available peak power to shave is $40 \%$ of the peak demand. According to the used peak shaving algorithm, the monthly shaved peak power is about $65 \%$ of this value, i.e., $26 \%$ of the peak demand. Another residential load profile was also investigated in which the average peak demand is $4 \mathrm{~kW}$ with the same load factor. The PW1 DC reduction savings increased under the second load profile because the shaved power increased. The average monthly shaved peak power, $\Delta P_{\text {shaved }}$, of the two load profiles can be used to indicate the beak-even analysis of the DC reduction by determining the rare that achieves the break-even.

\section{Conclusion}

The annual savings from a BMBES system depend on different technical and economic factors. The results showed that the economic feasibility of using BMBES for energy scheduling and DC reduction without renewables is critical under current prices of battery storage and existing electricity plans. Break-even analysis showed that the difference between the highest (on-peak) and lowest (off-peak) prices of the ToU plan plays a significant role in covering the capital cost of the BMBES. However, the price difference in most of the ToU plan offered by utilities is lower than the optimal value that achieves the break-even point. As a result, the NPW of the BMBES systems is negative under these plans. In some scenarios, BMBES units have a negative NPW with a certain payback period. This is because the payback period here is the simple payback period calculated as the accumulated annual cash flow disregarding the time value of the money. The time value of the money is considered in the NPW calculations. Therefore, for a scenario in which a system has a negative NPW, it still can be economically accepted if it has a payback period equal to or less than the analysis period. Accepted or not, the decision will depend on the customer's criteria he/she uses in budgeting for the system. For residential customers, the payback period criteria could be prudential for such a system that can also provide additional non-monetary benefits as a backup power source during blackouts. Over most of the analysis period, the savings from energy arbitrage are higher than the savings achieved from DC reduction by peak shaving for the same load profile. However, energy arbitrage imposes high degradation on the battery because of the daily deep cycling. In general, using BMBES for residential DC reduction is unprofitable under the current prices of the battery storage. Multiple value streams of BMBES by combining different services can be another approach to improve BMBES profitability.

\section{References}

[1] "Electricity Prices EIA." [Online]. Available: https://www.eia.gov/totalenergy/data/annual/showtext.p $\mathrm{hp} ? \mathrm{t}=\mathrm{ptb} 0810$.

[2] W. W. Hogan, "Time-of-use rates and real-time prices," pp. 1-8, 2014.

[3] A. S. Shariatzadeh and C. Lecompte, "Development of an energy management system for a network of distributed energy resources to provide backup power and accumulate savings on time-of-use prices and peak demand charges," in IEEE 36th International Telecommunications Energy Conference, 2014.

[4] R. Hledik, "Rediscovering residential demand charges," Electr. J., vol. 27, no. 7, pp. 82-96, 2014.

[5] A. Faruqui, "The movement towards deploying demand charges for residential customers," in NARUC 127th Annual Meeting, 2015.

[6] M. Lehrman, "Are residential demand charges the next big thing in electricity rate design?," Rocky Mountain Institute, 2015. [Online]. Available: https://rmi.org/news/residential-demand-charges-nextbig-thing-electricity-rate-design/. [Accessed: 01-Aug2016].

[7] R. Kamyar and M. M. Peet, "Optimal thermostat programming for time-of-use and demand charges with thermal energy storage and optimal pricing for regulated utilities," IEEE Trans. Power Syst., vol. 32, no. 4, pp. 2714-2723, 2017.

[8] W. Stone, "Demand charges mean big changes for electricity bills," Inside Energy, 2016.

[9] E. Hossain, M. Zawad, K. H. R. Islam, and Q. Akash, "Design a novel controller for stability analysis of microgrid by managing controllable load using load shaving and load shifting techniques; and optimizing cost analysis for energy storage system," Int. J. Renew. Energy Res., vol. 6, no. 3, 2016.

[10] G. Fitzgerald, J. Mandel, J. Morris, and H. Touati, "The economics of battery energy storage: How multi-use, customer-sited batteries deliver the most services and value to customers and the grid," Rocky Mountain Institute, 2015. [Online]. Available: http://www.rmi.org/electricity_battery_value. [Accessed: 01-Sep-2016].

[11]A. Oudalov, R. Cherkaoui, and A. Beguin, "Sizing and optimal operation of battery energy storage system for peak shaving application," in IEEE Lausanne Powertech Proceedings, 2007, pp. 1-5.

[12] A. Oudalov, D. Chartouni, C. Ohler, and G. Linhofer, "Value analysis of battery energy storage applications in power systems," in 2006 IEEE PES Power Systems Conference and Exposition, 2006, pp. 2206-2211.

[13] M. Long, T. Simpkins, D. Cutler, and K. Anderson, “A statistical analysis of the economic drivers of battery energy storage in commercial buildings," in 2016 North American Power Symposium (NAPS), 2016.

[14] A. K. Barnes, J. C. Balda, S. O. Geurin, and A. EscobarMejia, "Optimal battery chemistry, capacity selection, charge/discharge schedule, and lifetime of energy storage under time-of-use pricing," in 2nd IEEE PES International Conference and Exhibition on Innovative Smart Grid Technologies, 2011, pp. 1-7.

[15]K. Worthmann, C. M. Kellett, P. Braun, L. Grune, and 


\section{A.Zurfi et al. ,Vol. 2, No. 1, March, 2018}

S. R. Weller, "Distributed and decentralized control of residential energy systems incorporating battery storage," IEEE Trans. Smart Grid, vol. 6, no. 4, pp. 1914-1923, 2015.

[16] J. Münzberg, S. Baum, and I. Stadler, "Economic evaluation, optimization and comparison of photovoltaic-battery-grid power supply system in singleand multi-family buildings with increasing share of renewable energy," in International Energy and Sustainability Conference, 2016.

[17] J. Rogers, "Solar Power on the rise: rooftop solar, largescale PV, CSP, and the solar revolution," Union of Concerned Scientist, 2014. [Online]. Available: http://blog.ucsusa.org/john-rogers/solar-power-on-therise-rooftop-solar-large-scale-pv-csp-and-the-solarrevolution-618. [Accessed: 01-Apr-2017].

[18] "The Hidden Costs of Low Load Factor: White Paper," Colorado Springs Utilities, 2014. [Online]. Available: https://www.csu.org/CSUDocuments/hiddencostslowloa dfactor.pdf. [Accessed: 01-Apr-2017].

[19]B. Cheng and W. Powell, "Co-optimizing battery storage for the frequency regulation and energy arbitrage using multi-scale dynamic programming," IEEE Trans. Smart Grid, vol. PP, no. 99, pp. 1-10, 2016.

[20]A. Barnes and J. C. Balda, "Sizing and economic assessment of energy storage with real-time pricing and ancillary services," in 4th IEEE International Symposium on Power Electronics for Distributed Generation Systems, 2013, pp. 1-7.

[21] Y. J. Kim, G. Del-Rosario-Calaf, and L. K. Norford, "Analysis and experimental implementation of grid frequency regulation using behind-the-meter batteries compensating for fast load demand variations," IEEE Trans. Power Syst., vol. 32, no. 1, pp. 484-498, 2017.

[22] B. P. Bhattarai, K. S. Myers, and J. W. Bush, "Reducing demand charges and onsite generation variability using behind-the-meter energy storage," in IEEE Conference on Technologies for Sustainability, 2016, pp. 140-146.

[23] G. Carpinelli, S. Khormali, F. Mottola, and D. Proto, "Battery energy storage sizing when time of use pricing is applied," Sci. World J., vol. 2014, 2014.

[24]B. Aksanli and T. Rosing, "Optimal battery configuration in a residential home with time-of-use pricing," in IEEE International Conference on Smart Grid Communications, 2013, pp. 157-162.

[25] V. Viswanathan, M. Kintner-Meyer, P. Balducci, and C. Jin, "National assessment of energy storage for grid balancing and arbitrage," PNNL, 2013. [Online]. Available:

http://energyenvironment.pnnl.gov/pdf/National_Assess ment_Storage_PHASE_II_vol_1_final.pdf. [Accessed: 01-Dec-2016]. (last accessed on 25/03/2018)

[26] C. Heymans, S. B. Walker, S. B. Young, and M. Fowler, "Economic analysis of second use electric vehicle batteries for residential energy storage and loadlevelling," Energy Policy, vol. 71, pp. 22-30, 2014.

[27] E. N. Elkind, "Reuse and Repower: How to save money and clean the grid with second-life electric vehicle batteries," Center for Law, Energy \& the Environment Publications, 2014. [Online]. Available: http://scholarship.law.berkeley.edu/cleepubs/20/.

[Accessed: 01-Jul-2017].

[28] J. Neubauer and Ahmad Pesaran, "The ability of battery second use strategies to impact plug-in electric vehicle prices and serve utility energy storage applications," $J$. Power Sources, vol. 196, no. 23, 2011.

[29] L. Schirone and M. Macellari, "A techno-economical analysis of charge management in electrical vehicles," in International Conference on Renewable Energy Research and Applications, 2015, pp. 1253-1258.

[30] J. Leadbetter and L. Swan, "Battery storage system for residential electricity peak demand shaving," Energy Build., vol. 55, pp. 685-692, 2012.

[31] M. Zheng, C. J. Meinrenken, and K. S. Lackner, "Smart households: Dispatch strategies and economic analysis of distributed energy storage for residential peak shaving," Appl. Energy, vol. 147, pp. 246-257, 2015.

[32] C. Byrne and G. Verbič, "Feasibility of residential battery storage for energy arbitrage," in Australasian Universities Power Engineering Conference, 2013, no. October, pp. 1-7.

[33]R. Dufo-López and J. L. Bernal-Agustín, "Technoeconomic analysis of grid-connected battery storage," Energy Convers. Manag., vol. 91, pp. 394-404, 2015.

[34] "System Advisor Model Version 2016.3.14 (SAM 2016.3.14). National Renewable Energy Laboratory. Golden, CO." [Online]. Available: https://sam.nrel.gov/content/downloads. (last accessed on $25 / 03 / 2018$ )

[35]"Powerwall Daily Datasheet." [Online]. Available: https:/www.simplyenergy.com.au/docs/defaultsource/pdf/tesla_daily_powerwall.pdf?sfvrsn=4?redirect =no. [Accessed: 01-Dec-2015].

[36]"Powerwall 2 AC Datasheet." [Online]. Available: http://www.energymatters.com.au/wpcontent/uploads/2016/11/tesla-powerwall-2datasheet.pdf. [Accessed: 01-Feb-2017].

[37] N. DiOrio, A. Dobos, and S. Janzou, "Economic analysis case studies of battery energy storage with SAM," National Renewable Energy Laboratory (NREL), 2015. [Online]. Available: http://www.nrel.gov/docs/fy16osti/64987.pdf. (last accessed on 25/03/2018) [Accessed: 01-Jun-2016].

[38] "U.S. Inflation Calculator-Historical Inflation Rates," 2017. [Online]. Available:

http://www.usinflationcalculator.com/inflation/historical -inflation-rates/. (last accessed on 25/03/2018) 